\title{
Erratum to: Integrating new discoveries into the "vicious cycle" paradigm of prostate to bone metastases
}

\author{
Leah M. Cook • Gemma Shay • Arturo Araujo • \\ Conor C. Lynch
}

Published online: 6 August 2014

(C) Springer Science+Business Media New York 2014

Erratum to: Cancer Metastasis Rev (2014) 33: 511-525

DOI: 10.1007/s10555-014-9494-4

The original version of this article unfortunately contained a mistake. The third author's name was captured incorrectly. Instead of "Arturo Araujo", it was captured as "Arturo Aruajo". The correct author's name now appears above.

The online version of the original article can be found at http://dx.doi.org/ 10.1007/s10555-014-9494-4.

L. M. Cook $\cdot$ G. Shay $\cdot$ C. C. Lynch $(\bowtie)$

Department of Tumor Biology, Moffitt Cancer Center and Research

Institute, 12902 Magnolia Dr., SRB-3, Tampa, FL 33612, USA

e-mail: conor.lynch@moffitt.org

\section{A. Araujo}

Department Integrated Mathematical Oncology, Moffitt Cancer

Center and Research Institute, Tampa, FL, USA 